\title{
A rare case of mucoepidermoid carcinoma of the skin: A case report and a literature review
}

\author{
Marcello Filotico ${ }^{1}$, Francesca Mazzeo*2 \\ ${ }^{1}$ Fondazione Card. Panico, Azienda Ospedaliera, Tricase(le), Italy \\ ${ }^{2}$ Ospedale Metropolitano Bianchi, Melacrino, Morelli, Reggio Calabria, Italy
}

Received: September 11, 2021

Accepted: October 22, 2021

Online Published: November 24, 2021

DOI: $10.5430 /$ crcp.v9n1p1

URL: https://doi.org/10.5430/crcp.v9n1p1

\begin{abstract}
This report presents the case of primary Mucoepidermoid Carcinoma of the skin on the leg of a 74-year-old man. The epidemiological data of the neoplasm are examined, and the morphological picture and immunophenotypic profile are compared with those of the homologous tumor of the salivary glands. According to the scoring system of this type of tumor, our case is classified as low-grade.
\end{abstract}

Key Words: Mucoepidermoid carcinoma, Skin, Immunohistochemistry

\section{INTRODUCTION}

Mucoepidermoid carcinoma (MEC) is a type of salivary gland tumor that has been exceptionally found in body parts such as the skin. The discovery of a tumor in the skin with these characteristics merits reporting.

\section{CASE PRESEntation}

For several months, the 74-year-old man has experienced a smooth, painless, slow-growing subcutaneous nodular swelling on the external aspect of his left thigh.

With the clinical suspicion of a sebaceous cyst, she undergoes an outpatient excisional biopsy including together with the neoformation a flap of skin and superficial subcutaneous tissue.

\subsection{Materials and methods}

The material taken to the surgery is fixed in toto with buffered formalin and embedded in paraffin. Some sections are stained with hematoxylin and eosin, while others are treated with the PAS reaction. The material is also tested with an antibody panel comprising: k7, EMA, P63, P 40, and CEA.

The surgical specimen consists of a skin flap a thin subcutaneous layer. In the medium-deep dermis, bordering on the hypodermis, there is a rounded nodular formation with a diameter of $1.7 \mathrm{~cm}$. The formation is grayish pink color, with a smooth and shiny surface and a soft consistency.

\subsection{Histology}

At low magnification, both can appreciate the neoformation in all its entirety. It is evident that it is detached from the epidermis, which is separated from a band of fibrous tissue. The mass has two different morphological patterns: The peripheral part appears to be compact, while the central part has numerous cystic cavities of various sizes (see Figure 1a). At higher magnification, the solid component appears to be made up of tightly packed glandular tubules that are covered

\footnotetext{
* Correspondence: Francesca Mazzeo; Email: mazzeoframed@live.it; Address: Ospedale Metropolitano Bianchi, Melacrino, Morelli, Reggio Calabria, Italy. 
by a single-line high cylindrical epithelium with basophilic cytoplasm in whose lumen there often exists an amorphous basophilic material (see Figure 1b, 1c). Moreover, there are acinar formations with cribriform aspects (see Figure 1c). In the inner zone, three cell types can be distinguished: polyhedral cells with small- to medium-sized amphophilic cytoplasm (intermediate cells) (see Figure 2a), cells with vacuolized cytoplasm (clear cells) (ss Figure 2b), and polyhedral cells of greater volume connected to one another epidermally (epidermoid cells) (see Figure 2c, 2d). Furthermore, foci of complete epidermization are detected with the production of lamellar keratin material (see Figure 3b, 3c), and collections of amorphous basophilic mucinous material are present in the cystic cavities and between the cells of the intercystic septa (see Figure 3b, 3d). Intermediate and clear cells are preferably located in the septa that separate the cystic cavities, whereas epidermoid cells are preferably found towards the walls of the cystic cavities, where they protrude in the form of nodules (see Figure 2d). The lumen of the cystic cavities is occasionally occupied by clusters of keratinizing squamous cells, mucus, and/or laminated keratin material (see Figure 3a, 3b, 3c, 3d). The epidermization resembles epidermal metaplasia rather than squamous neoplastic proliferation (see Figure 3b).
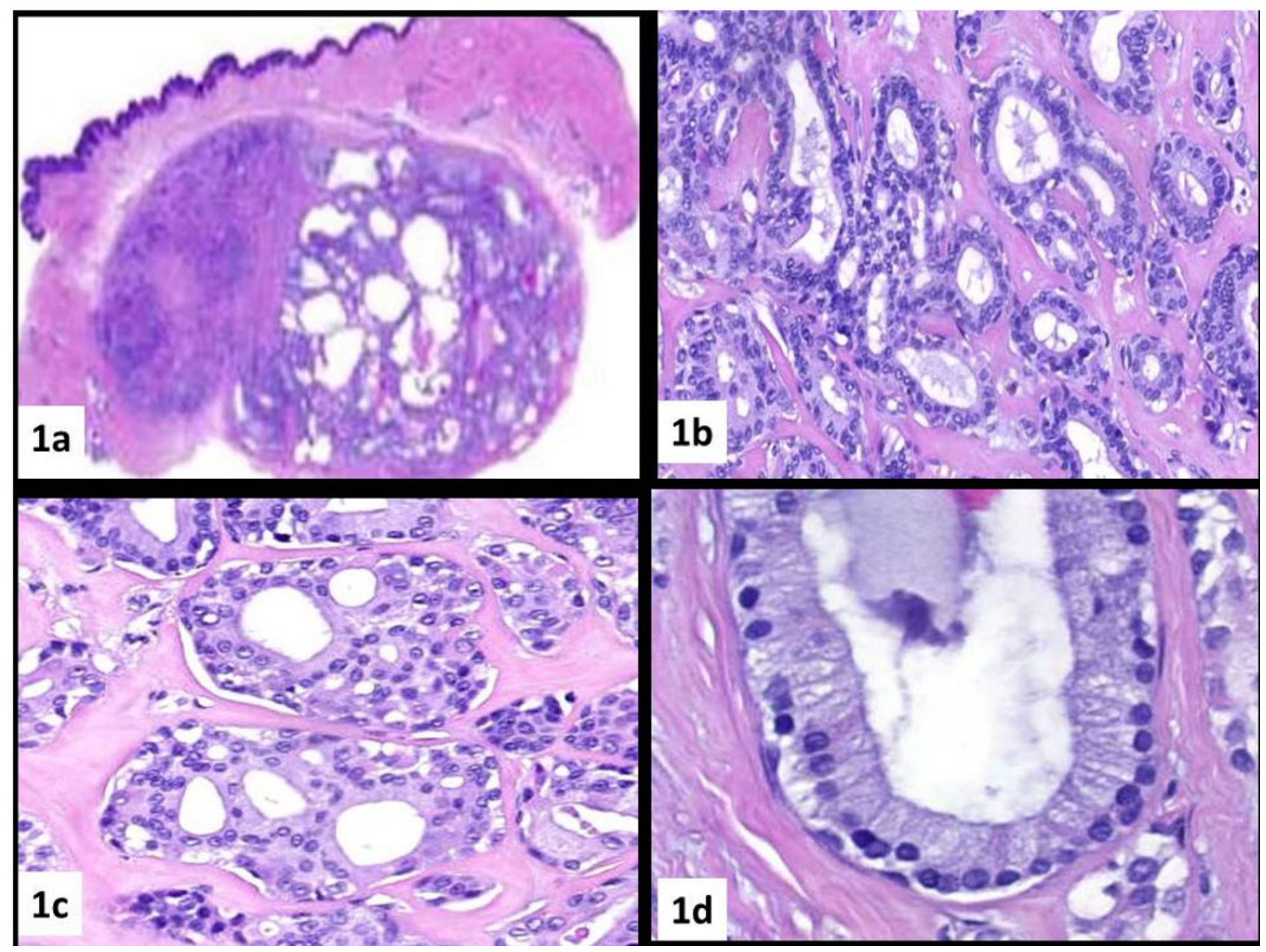

Figure 1. a) Low magnification of the neoplastic nodule. The distance from the epidermis, the solid peripheral component, and the central multicystic component are evident. HE 4X; b) Tubular component in the solid area. HE 75X; c) adenoid cystic acini in solid area HE 175X; d) Mucous tubular cells EH 250X.

The PAS reaction is intensely positive in the amorphous material contained in the glandular lumens, in the border of the clear cells and the cytoplasm of the cells that delimit the cystic cavities, and in the amorphous mucoid material (see Figure $4 \mathrm{~b}$ ), whereas the intermediate and epidermoid cells are weakly positive (see Figure 4a, 4c, 4d). 


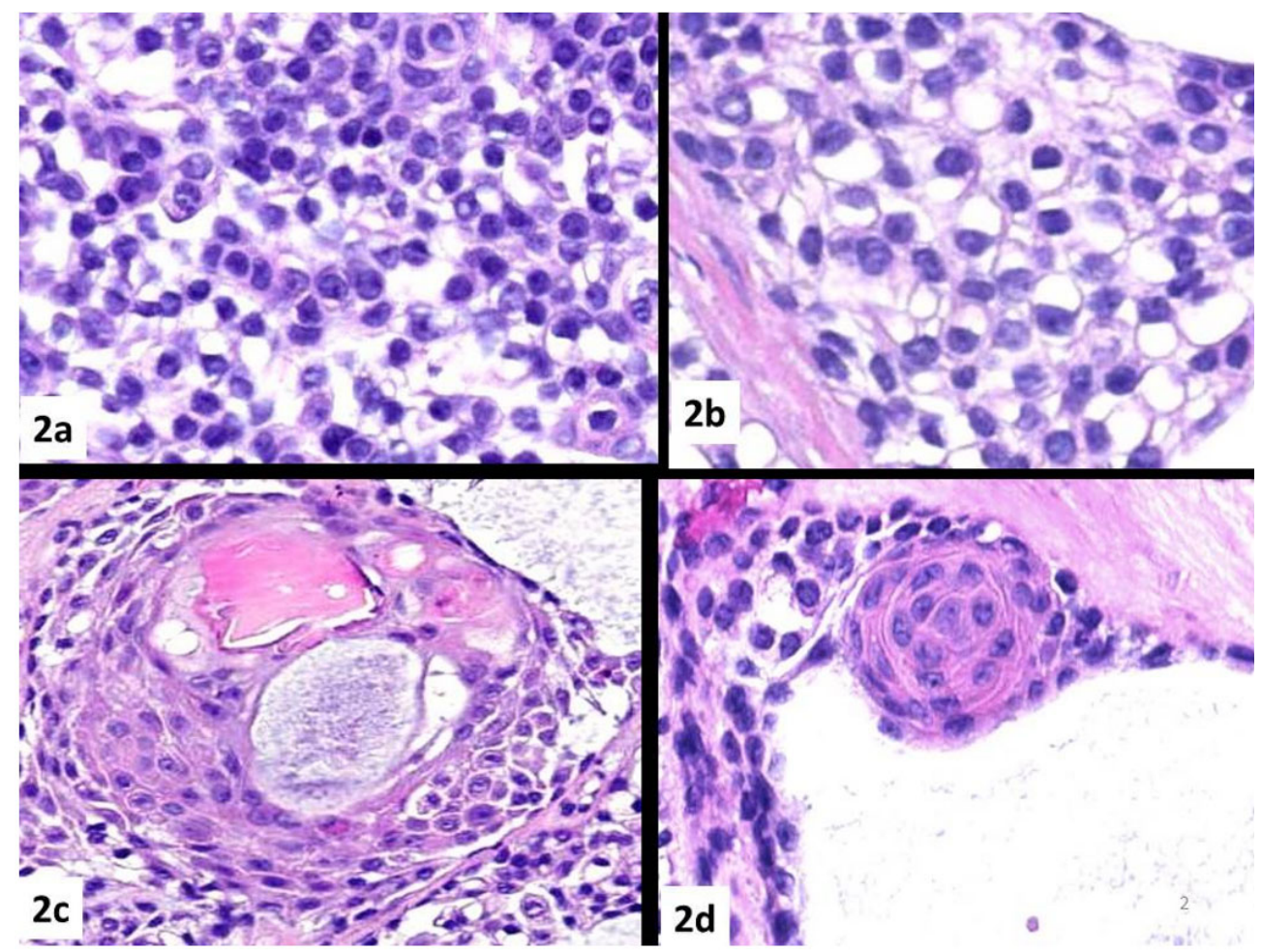

Figure 2. a) Intermediate cells HE 250X; b) Clear cells $250 \mathrm{X}$, c) Epidermoid cells delimiting two microcysts, one containing mucus (basophilic), and the other with keratin (acidophilic) HE $250 \mathrm{X}$; d) Nodule of epidermoid cells in the wall of a cyst HE 250X.

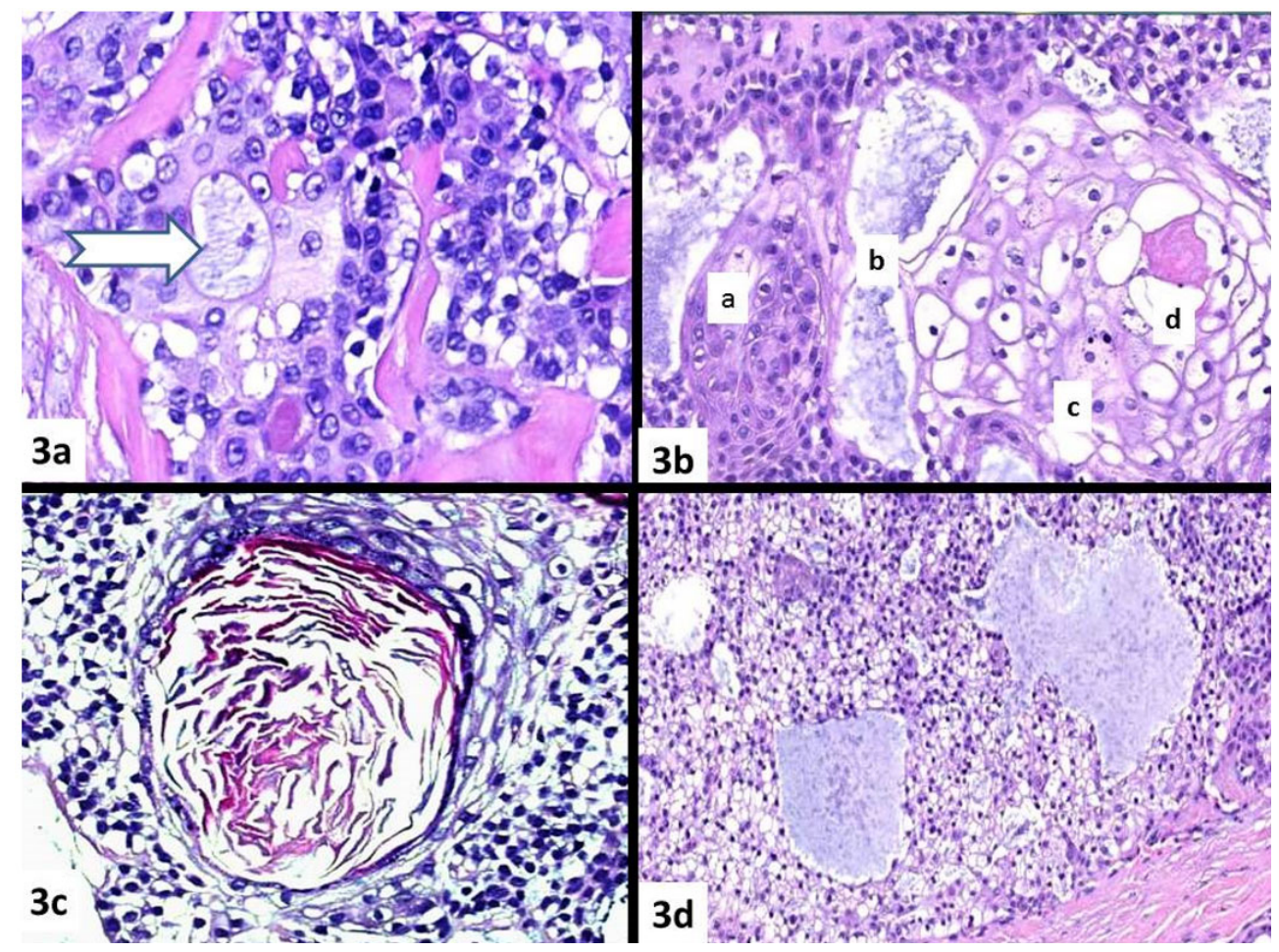

Figure 3. a) Mucogenic cells (arrow) surrounded by intermediate cells HE 125X; b) A group of epidermoid cells (i) surrounding two small mucus-containing cysts (ii) group of cells in mature epidermoid metaplasia, (iii) keratin material, and (iv) HE 125X; c) Lamellar keratin material HE 125 X; d) Two collections of mucus HE 75X. 


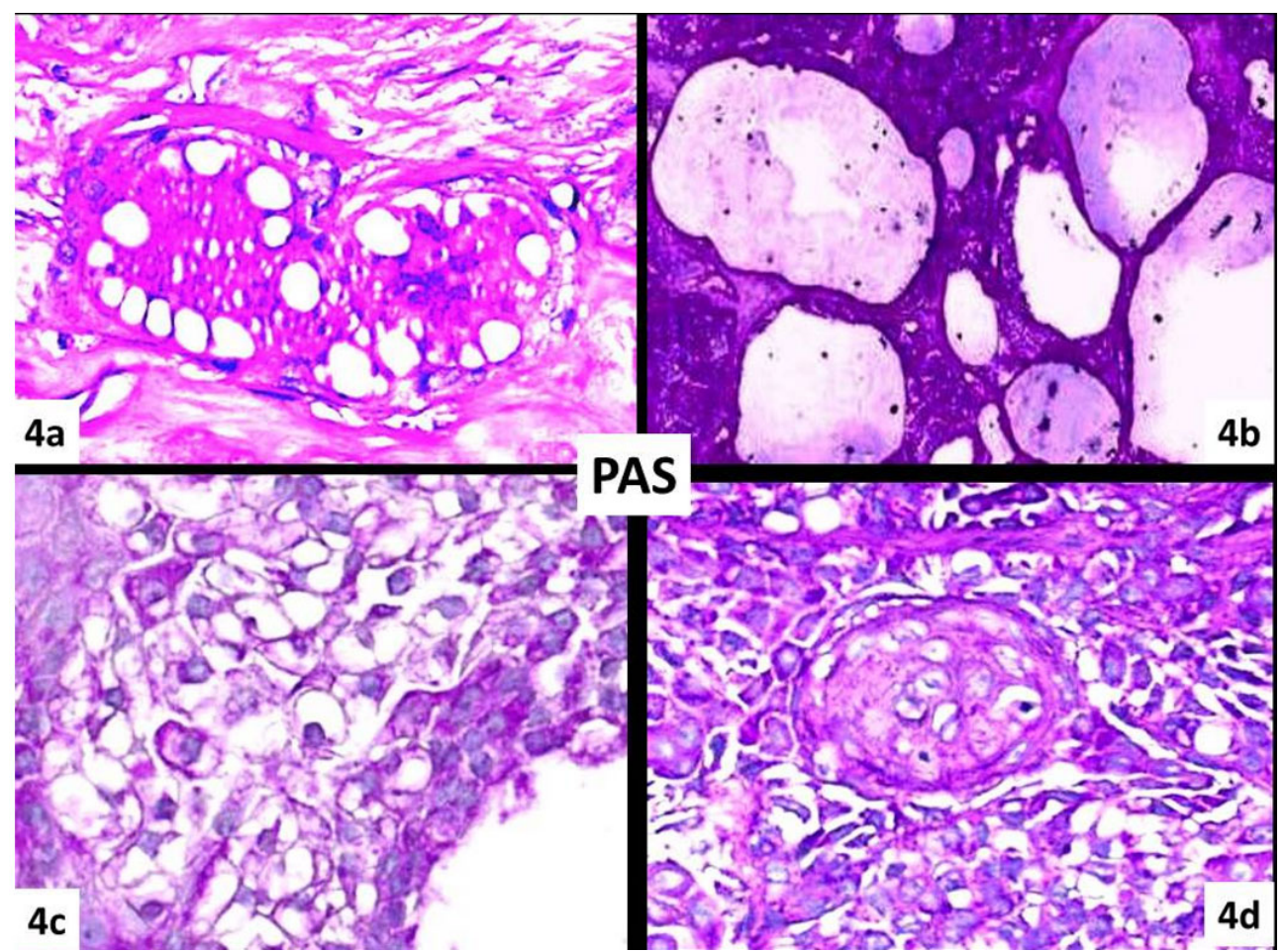

Figure 4. PAS reaction in mucus-producing glands in (a) mucus-containing cysts, (b) a clear cell membrane, (c) epidermoid cells, and (d) HE 150X.

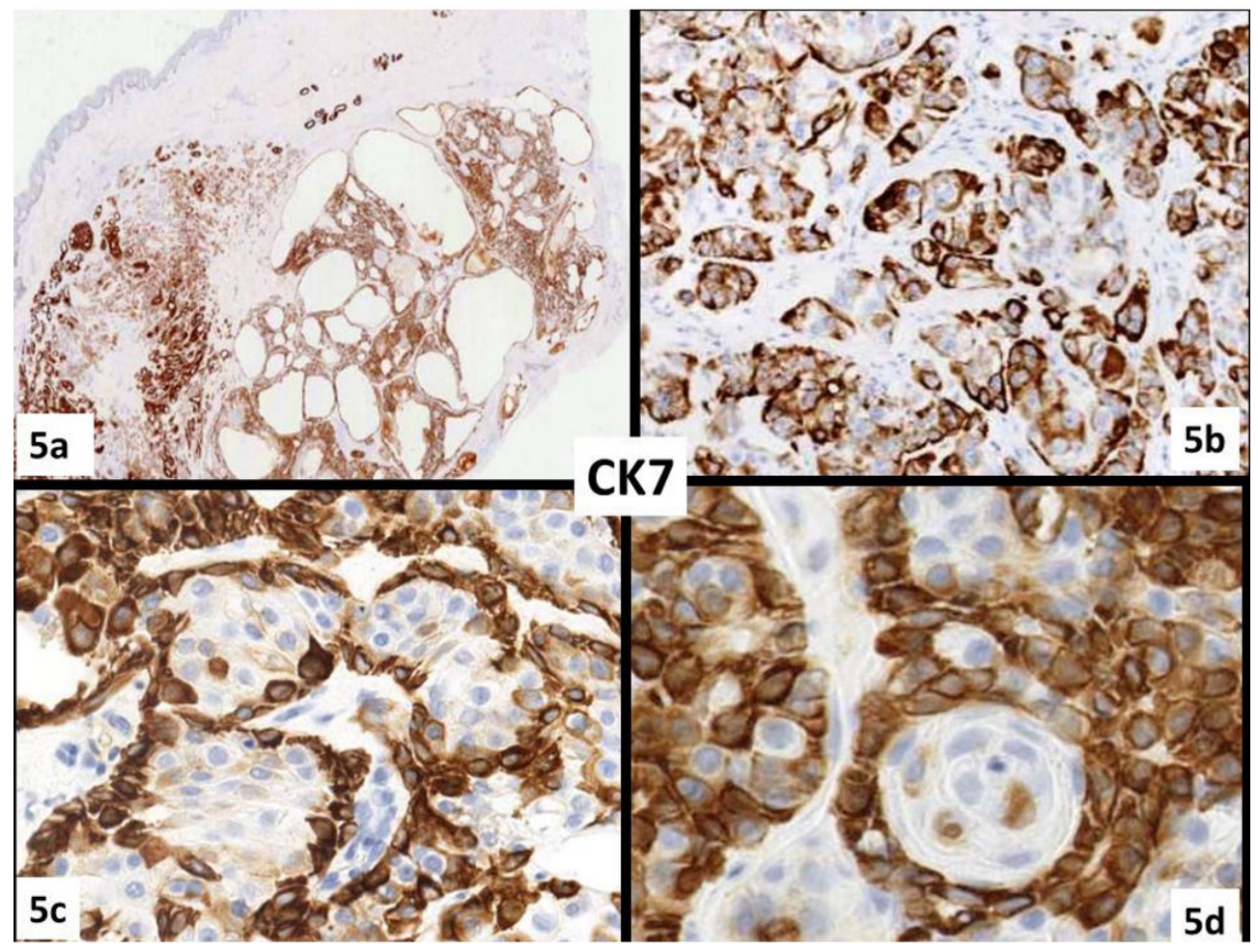

Figure 5. CK7 a) Overview of the nodule. Reactivity is present in both sectors (10X); b) Tubular structures of the peripheral area are intensely and diffusely reactive (125X); c) Multicystic area. Cell nests with a negative central core surrounded by an intensely reactive ring of cells. The cells of the peripheral ring show the characteristics of the intermediate cells, while those of the core show those of the epidermoid cells (150X); d) Nest of epidermoid cells with corticoid arrangement (150). 


\subsection{Immunohistochemistry}

CK 7 is abundantly expressed in both the peripheral and central regions of the nodule (see Figure 5a). The elements of the peripheral tubular component are intensely and uniformly positive (see Figure $5 b$ ). There are two cellular components in the polycystic, one intensely positive and one distinctly negative. These two components combine to form acinar structures, with the positive component positioned on the periphery of the acinus, while the negative component constitutes its core nucleus. The central cells have a larger cytoplasm and are occasionally arranged in onion bulbs (see
Figure 5c, 5d). EMA is broadly expressed in the peripheral region of the nodule, whereas it is expressed in sporadic elements usually close to the cystic walls in the polycystic area. The epidermoid cells are clearly negative $\mathrm{P} 63-\mathrm{P} 40(\Delta \mathrm{NP} 63)$ (see Figure 6a, 6b, 6c, 6d). P 63 is highly expressed in the peripheral tubules, which is an acinar component (see Figure $7 \mathrm{a}, 7 \mathrm{~b}, 7 \mathrm{c})$. In multicystic area, the intermediate cells express an intense and widespread positivity. The epidermoid cells show less frequent expressiveness, as they tend to evolve towards epidermization and keratinization (see Figure 8a, $8 b)$.

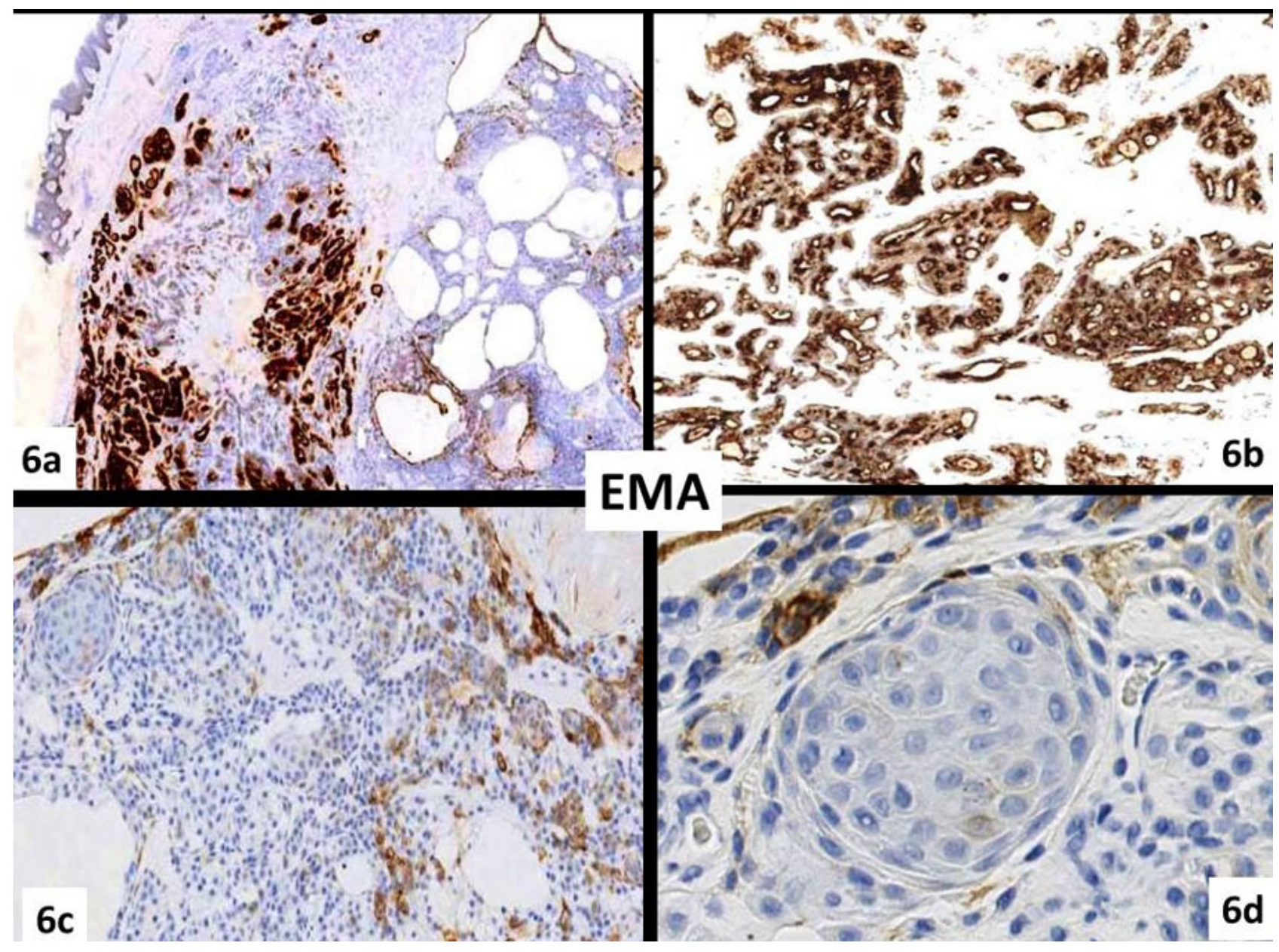

Figure 6. EMA - a) Reactivity is limited to the peripheral part, while that in the multicystic area is completely negative $(10 \mathrm{X})$; b) Tubular area is diffusely and intensely positive $(75 \mathrm{X})$; c) Widespread negativity of the intercystic cell component (50X); d) Epidermoid cell nest negative (150X).

In contrast to $\mathrm{P} 63, \mathrm{P} 40$ is widely expressed by the epidermoid cells, as well as by those in mature epidermization (see Figure 8c, 8d).
CEA is focally expressed by the luminal cells of the tubules and by the mucosecerning cells of the glandular acini and cystic walls. It is also present in the intraluminal mucus (see Figure 9a, 9b, 9c, 9d). 


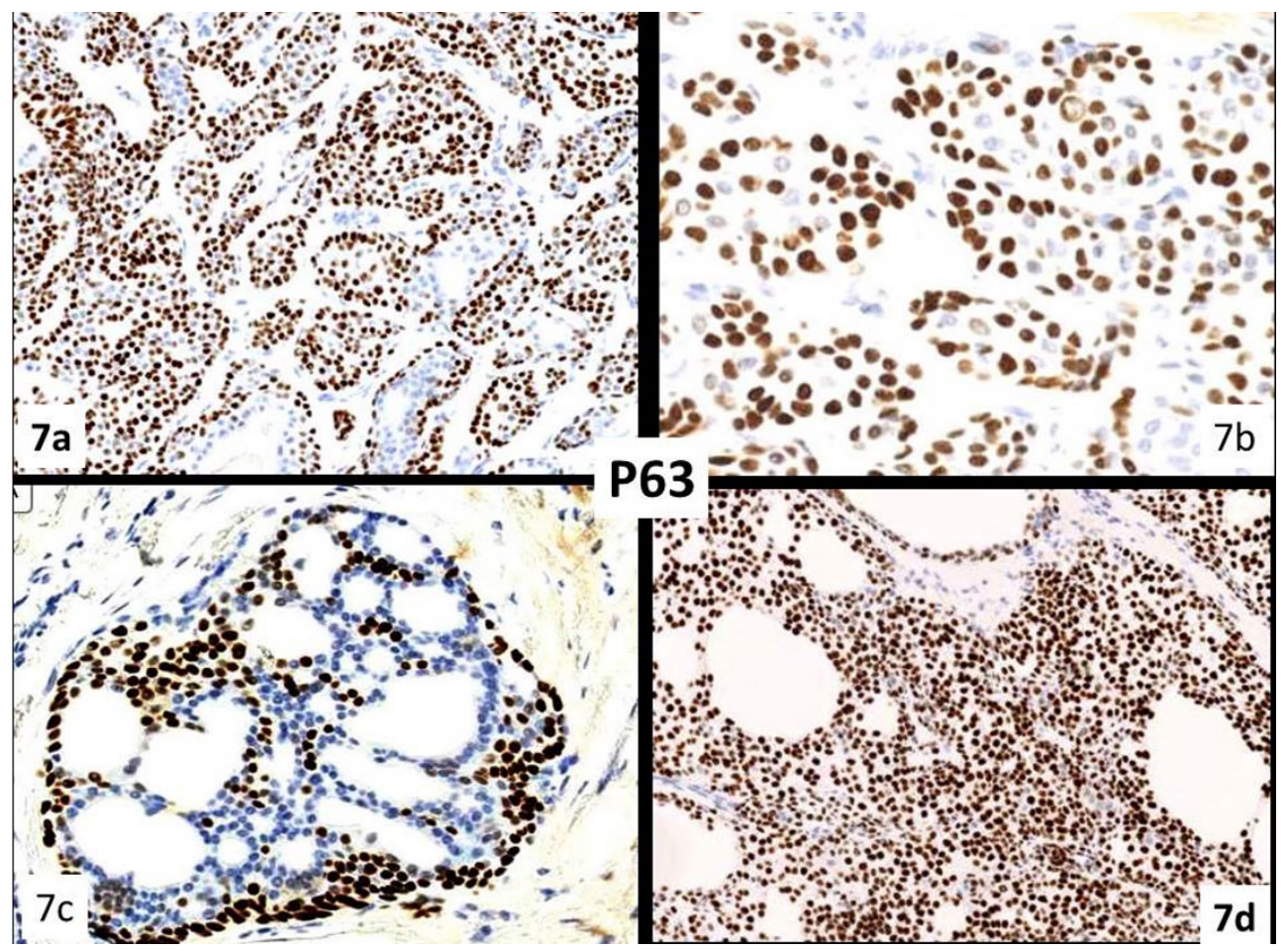

Figure 7. P63 - a) \& b) Tubular area (150X); c) Adenoid cystic acinus; d) Intermediate cells (150X).

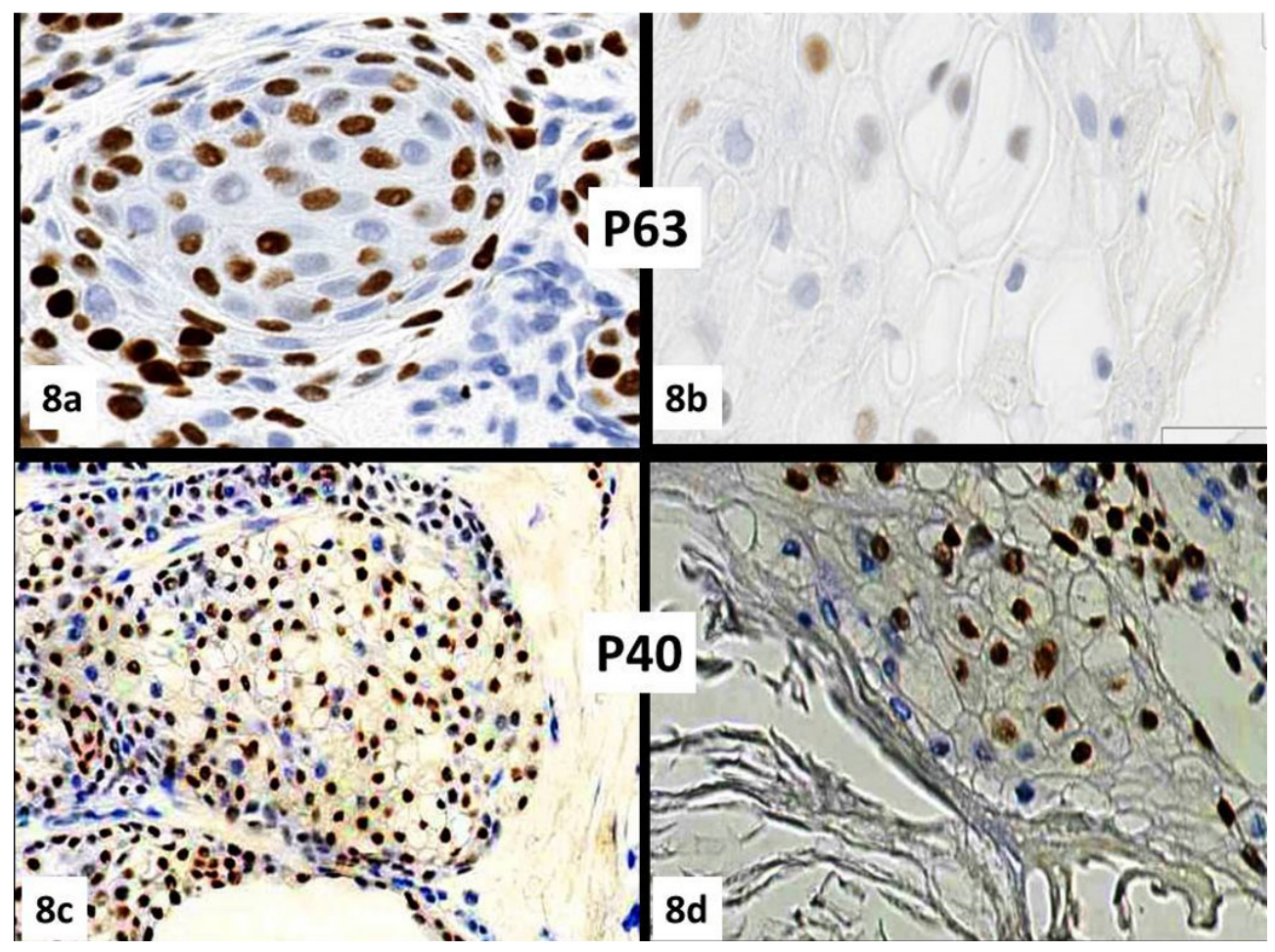

Figure 8. P63 -a) Epidermoid cell nodule. Rare positive elements (200X); b) Group of cells in mature epidermis lack expressiveness (200X); P40 - c) nodule of epidermal cells. All elements are positive (150X); d) - Group of cells in matira and dermization. Almost all the elements show positivity (200X). 


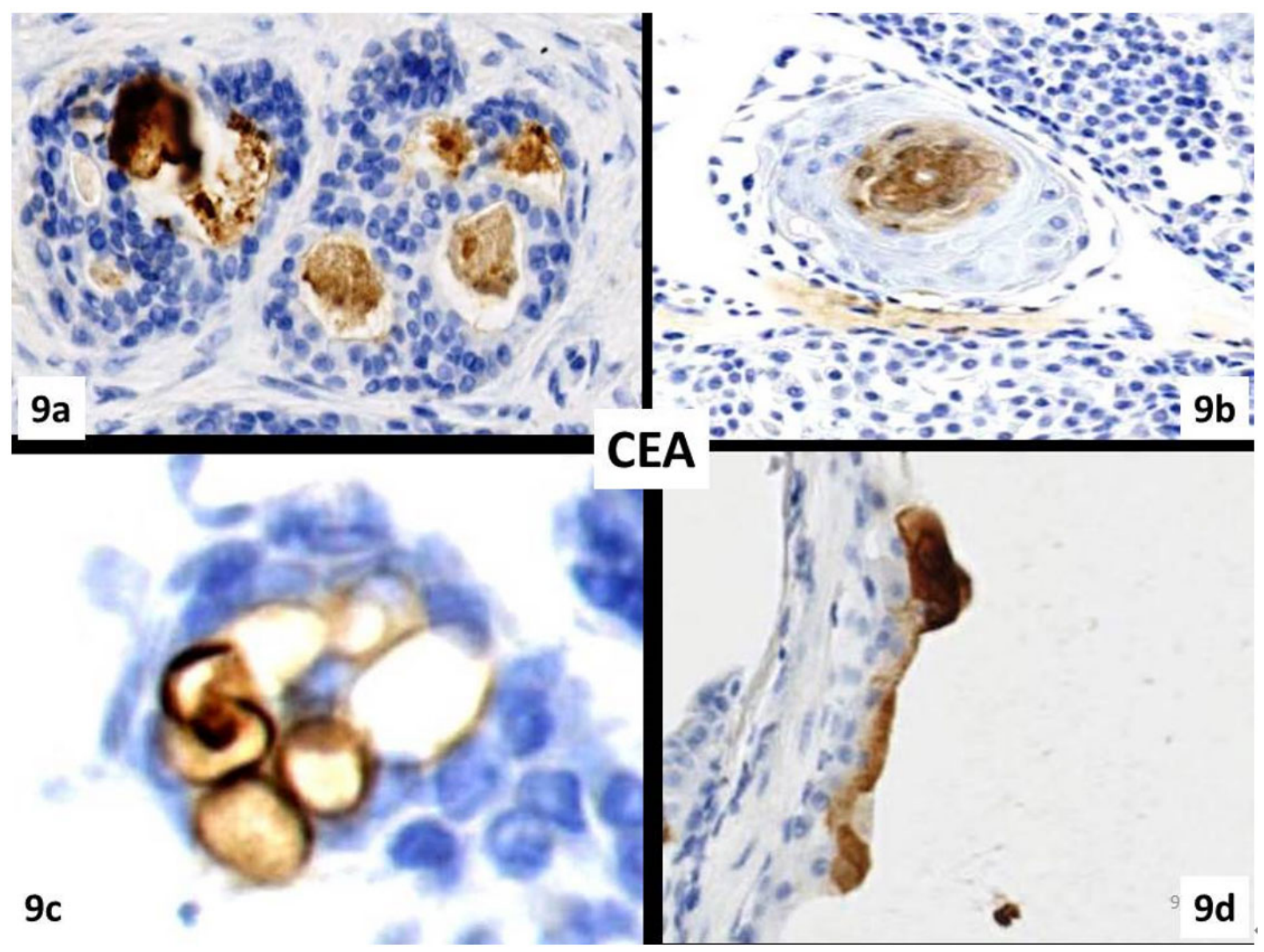

Figure 9. CEA - a) Adenocystic acinus; b) Luminal cells in glandular tubule; c) \& d) Mucigenic cells (150X).

\section{DisCUSSION}

It is difficult to determine the true prevalence of primary MEC of the skin. A recent retrospective study based on the Surveillance, Epidemiology, and End Results database from 1975 to 2016 revealed 141 occurrences of MEC that is apparently primitive of the skin. ${ }^{[1]}$ In $97 \%$ of the cases, the lesion was located in the head and neck areas, making it plausible to suppose that a good part of them derived from major, minor, or aberrant salivary structures. As revealed by numerous writers, another challenge in determining the real incidence of this lesion is that it is frequently diagnosed but mistaken for adenosquamous carcinoma (ASC). A review of the literature dating back to 2005 reveals 30 cases of primary MEC of the skin. After studying the iconographies of the articles, the reviewer (Riedlinger) concludes that only eight of these cases, including our own, are admissible as legitimate cases of MEC. ${ }^{[2]}$ Later, the literature reported seven more reports. ${ }^{[3-8]}$ Table 1 summarizes the data reported by Riedlinger addressing those present in the literature after 2005.

In this small number of cases, a gender preference was not witnessed. The average age is around 60 years, with a range of 7 to 83 years. In 9 out of 14 cases, the lesion was located in the head and neck region.

Table 1. The data reported by Riedlinger addressing those present in the literature after 2005

\begin{tabular}{cccc}
\hline Case & Ref & Age/Sex & Site \\
\hline 1 & $* 12$ & $54 \mathrm{~F}$ & Foot \\
2 & $* 42$ & $52 \mathrm{~F}$ & Neck \\
3 & $* 22$ & $60 \mathrm{M}$ & Ear \\
4 & $* 31$ & $31 \mathrm{~F}$ & Finger \\
5 & $* 45$ & $85 \mathrm{~F}$ & Low eyelid \\
6 & $* 15$ & $75 \mathrm{M}$ & Finger \\
7 & $* 6$ & $72 \mathrm{M}$ & Forhead \\
8 & 2 & $79 \mathrm{~F}$ & Axilla \\
9 & 3 & $41 \mathrm{M}$ & EAC \\
10 & 4 & $83 \mathrm{M}$ & Cheek \\
11 & 5 & $76 \mathrm{M}$ & Cheek \\
12 & 6 & Child & Scalp \\
13 & 7 & $53 \mathrm{~F}$ & Scalp \\
14 & 8 & $83 \mathrm{~F}$ & Dorsum nose \\
15 & Our case & $74 \mathrm{M}$ & Leg \\
\hline
\end{tabular}

The first problem is whether and to what degree these lesions are morphologically and clinically assimilable with the ho- 
mologous tumors of the salivary glands. The second concern is the differential diagnosis criteria for ASC, which is this tumor is sometimes mistaken for.

The characteristics of salivary lesion's cell types, described as "intermediate cells", "clear cells", "epidermoid cells" and "mucous cells", are also presented. The intermediate cells are roundish mononuclear elements of small volume with scarce cytoplasm that are found throughout the tumor (see Figure 2a). The clear cells have optically empty cytoplasm and a small nucleus that is central or attached to the cell membrane (see Figure 2b). Lastly, the epidermoid cells have a wider, amphophilic cytoplasm that tends to aggregate in clusters and is frequently found leaning against the wand (see Figure 3a, 3b, 3c). Collections of amorphous basophilic material (see Figure 3d).

Numerous studies have been conducted on the immunophenotypic expressivity of MEC, and for them, multiple antibodies have been used. The results were not always consistent. ${ }^{[9]}$ Therefore, obtaining a precise picture of this lesion's immunophenotypic profile is quite difficult.

The immunostochemical panel we used has shown that, in the solid zone where tubular structures prevail, CK7 is diffusely expressed; in the multicystic area, on the other hand, the positive cells delimit nodular structures made up of distinctly negative cells (see Figure 5a, 5b, 5c, 5d).

EMA is most prominent in the solid zone, where tubular structures are predominant. However, in the multicystic area, it can be considered as practically unexpressed (see Figure $6 \mathrm{a}, 6 \mathrm{~b}, 6 \mathrm{c}, 6 \mathrm{~d})$.

Tubular, glandular, and intermediate cells are strongly and diffusely reactive to $\mathrm{P} 63$ and $\mathrm{P} 40$, which are antibodies that are indicated as markers of myoepithelial or squamous differentiation, respectively (see Figure 7a, 7b, 7c, 7d).

In epidermoid and squamous mature cells, the positivity for P63 gradually decreases with the progress of epidermization, while the positivity for $\mathrm{P} 40$ persists and affects the totality of the elements (see Figure 8a, 8b, 8c, 8d).

CEA is expressed by the luminal cells of the gander tubules and by the mucous cells of the adenoid cystic acini and the cystic walls (see Figure 9a, 9b, 9c, 9d).

Once the substantial morphological and immunophenotypic identity has been established, the grading standards for homologous salivary tumors can be applied to our case.

As can be seen in the table above, the lesion in our case received a score of 0 and is, thus, considered to be of low grade. Therefore, it does not merit inclusion in the differential diagnosis with the much more aggressive ASC, a high-grade tumor. The differential diagnostic characteristics of ASC are summarized in the following table.

Table 2. DD DIAGNOSIS MEC vs. ASC

\begin{tabular}{llll}
\hline Score Grading & Pt & Our Case & Pt \\
\hline Cystic component $>20 \%$ & +2 & $50 \%$ & 0 \\
Perineural invasion & +3 & - & 0 \\
Necrosis & +3 & - & 0 \\
4 or+ mitotsis x 10HPF & +3 & - & 0 \\
Anaplasia & +4 & - & 0 \\
The score of our case PT & & $=$ & 0 \\
Scoring: & & \\
Low Grade (0-4) & & \\
Intermediate Grade (5-6) & & \\
High grade ( $\geq 7)$ & & \\
\hline Note. The AFIP and Brandwein et al.'s ${ }^{[10-12]}$ grading systems.
\end{tabular}

The differential diagnosis between MEC and ASC is often very difficult, so much so that these two lesions have been considered by some to be a single entity. Only an accurate evaluation of the morphological characteristics of the lesion can allow its differentiation (see Table 3 ).

Table 3. DD DIAGNOSIS MEC vs. ASC

\begin{tabular}{|l|l|l|}
\hline Intraepidermal carcinoma & - & + \\
\hline WD adenocarcinoma & - & + \\
\hline Dermal-based solid/cystic tumor & + & - \\
\hline Papillary features & + & - \\
\hline Mucogenic cells & + & - \\
\hline Peritumoral fibrosis & + & - \\
\hline High-grade nuclear features & - & $+/-$ \\
\hline
\end{tabular}

Note. From Gartell ${ }^{[5]}$.

\section{Conclusions}

From this case study, as well as from the examination of the literature, the following conclusions can be drawn:

a) Cutaneous ECM is an extremely rare event, and the cases reported in the literature amount to a few dozen.

b) The lesion studied in this report, from a morphological perspective, is similar to the homologous salivary tumor.

c) The immunophenotypic profile presents some characteristics that we have not seen emphasized elsewhere:

CK7 is diffusely positive in the cells of the tubular fraction. In the cellular population of septa interposed between the cystic cavities, the cells show varied levels of expressiveness that give rise to acinar formations where CK-positive cells surround the central nucleus of CK-negative cells.

Ema is exclusively expressed by the tubular component.

In epidermoid cells and cells in mature epidermization, the proportion of P63-positive cells gradually decreases with the 
progress of the squamous maturation process, while the cellular fraction is represented almost exclusively by P40-postive cells.

d) What histogenetic meaning to be given to these immunophenotypic expressions is not easy to determine. We can only say that the so-called "epidermoid cells" and the frankly squamous cells show an immunophenotypic profile that differs from the tubular and intermediate cells, with the progressive loss of the myoepithelial immunophenotypic profile and the conservation of the epithelial one to which the morphological characteristics of the epidermoid and squamous elements correspond. Therefore, the score of 0 assigned to our case indicates that the legion we studied is of a low grade.

\section{CONFlicts of InTEREST Disclosure}

There is no conflict of interest.

\section{REFERENCES}

[1] Maloney NJ, et al. Primary mucoepidermoid carcinoma of the skin: a retrospective investigation in the Surveillance, Epidemiology, and End Results Database from 1975 to 2016. Int. J. Dermatol. 2020; 59: e169-e171. https://doi.org/10.1111/ijd.14749

[2] Riedlinger WFJ, et al. Mucoepidermoid carcinoma of the skin: A distinct entity from adenosquamous carcinoma: A case study with a review of the literature. Am. J. Surg. Pathol. 2005; 29: 131-5. PMid:15613868. https : //doi.org/10.1097/01.pas . 0000147 $397.08853 .6 \mathrm{f}$

[3] Bared A, et al. Mucoepidermoid carcinoma of the external auditory canal (EAC). Acta. Otolaryngol. 2007; 127: 280-4. PMid:17364365. https ://doi .org/10.1080/00016480600818120

[4] López V, et al. Primary cutaneous mucoepidermoid carcinoma. Am. J. Dermatopathol. 2010; 32(6): 618-20. PMid:20534987. https : //doi.org/10.1097/DAD.0b013e3181cdad06

[5] Gartrell R, et al. Primary cutaneous mucoepidermoid carcinoma: a case study with a review of the literature. Int. J. Surg. Pathol. 2015; 2: 161-4. PMid:25319051. https ://doi.org/10.1177/106689 6914554834

[6] Berk Lennerz JK, et al. Mucoepidermoid carcinoma on the scalp of a child. Pediatr. Dermatol. 2007; 24: 452-3. PMid:17845193. https ://doi.org/10.1111/j.1525-1470.2007.00484.x

[7] Junewicz A, et al. Primary cutaneous vs. parotid mucoepidermoid carcinoma of the scalp: A case report. Am. J. Otolaryngol. 2015; 36:
463-6. PMid:25708819. https://doi.org/10.1016/j.amjoto .2015 .01 .014

[8] Gupta M. Primary cutaneous mucoepidermal carcinoma. BMJ Case Rep. 2017; 2017: bcr2017223080. PMid:29191824. https://doi. org/10.1136/bcr-2017-223080

[9] Coca-Pelaz A, et al. Salivary mucoepidermoid carcinoma revisited. Eur. Arch. Otorhinolaryngol. 2015; 272: 799-819. PMid:24771140. https://doi.org/10.1007/s00405-014-3053-z

[10] Goode RK, et al. Mucoepidermoid carcinoma of the major salivary glands: clinical and histopathologic analysis of 234 cases with evaluation of grading criteria. Cancer. 1998; 82: 1217-24. https://doi.org/10.1002/(SICI) 1097-014 2(19980401) 82:7<1217: : AID-CNCR2>3.0.CO;2-C

[11] Auclair PL, et al. Mucoepidermoid carcinoma of intraoral salivary glands. Evaluation and application of grading criteria in 143 cases. Cancer. 1992; 69: 2021-30. https://doi.org/10.1002/1097-0142(19920415)69: 8<2021: : AID-CNCR2820690803>3.0.CO;2-7

[12] Brandwein MS, et al. Mucoepidermoid carcinoma: a clinicopathologic study of 80 patients with special reference to histological grading. Am J Surg Pathol. 2001; 25: 835-45. PMid:11420454. https ://doi.org/10.1097/00000478-200107000-00001

[13] Shin-Ichiro M, et al. Differential expression of p63 isotypes (DN and TA) in salivary gland neoplasms: biological and diagnostic implications. Human Pathology. 2005; 36: 821-7. PMid:16084953. https://doi.org/10.1016/j.humpath.2005.05.014 